\section{One Size Fits All? Really?}

As I write this, CMS is closing the window of opportunity for comments on their new proposal to reduce documentation and provide a blended payment for "Evaluation and Management" (E/M), code levels 2-5. Although I applaud their effort to give doctors more time to spend with their patients, this just seems like an effort to pay less to physicians who care for complex cases.

The reimbursement schemes for medical oncology have never made sense. Medicare rates, even at levels 4 and 5, are insufficient to maintain the bottom-line in any practice. Oncologists need to sell drugs to stay in business, and because of some changes in that regard, many have resorted to hospital-based practices for economic security. But this new plan will affect both facility- and community-based practitioners. Even CMS has estimated that the overall reduction in revenue will approach 7\%. They maintain that there will be an "add-on" code for complex patients to compensate for this reduction, but it is not clear what criteria or documentation must be met for this and whether this compensation would fill the gap.

We need reimbursement reform, but this doesn't even come close. A blended payment might improve revenue for physicians who provide care such as "well-baby checks," but very few patients with cancer fall into that category. Our patients often have life-threatening disease, are usually receiving complicated and toxic therapies, and often have multiple comorbidities. In my opinion, we need increased payments for $\mathrm{E} / \mathrm{M}$ codes across the board, and we need a payment for chemotherapy management to support the intense nursing navigation required to coordinate care and to support these patients throughout their journey. I won't even get into the complexities of buying and selling drugs. Appropriate reimbursement for administering drugs is definitely needed. Buying and selling drugs, in my opinion, should end.

The argument that reducing documentation will save physicians' time doesn't even make much sense anymore. With the advent of the electronic medical record and its implementation in virtually all practices, it has become increasingly easier to fulfill the current documentation requirements. Building smart phrases that can be easily parked into your notes is a breeze-even for this Luddite. I can't type well, but I have Dragon software, so I can easily update a patient's record through dictation. Of course, my Dragon isn't too smart, but that's another story. Laboratory work, imaging reports, and even problem lists can be engineered to autofill your notes, and these can, with a click, be sent to every other provider caring for each individual. I rarely have to stay late anymore to complete charting. I'm glad I survived long enough to see that happen!

To sum it up, CMS has it wrong again. Let's hope the Agency sees the light and maybe, just maybe, we can take positive steps toward true reimbursement reform that will appropriately support all physicians in non-procedure-based specialties.

What do you think? Please e-mail correspondence (include contact information) to JNCCN@nccn.org or log into www.editiorialmanager.com/JNCCN to submit a Letter to the Editor.

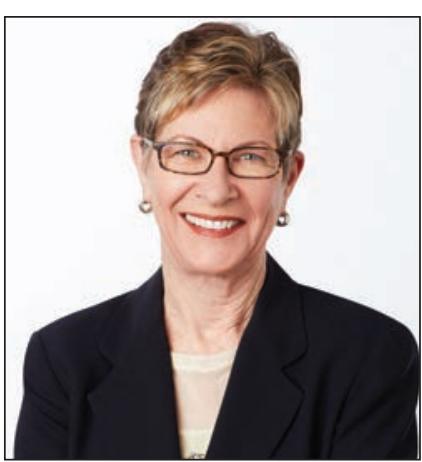

Margaret Tempero, MD

Margaret Tempero, MD, is a Professor of Medicine and Director of the UCSF Pancreas Center and editor-in-chief of JNCCN. Her research career has focused on pancreatic ductal adenocarcinoma, especially in the area of investigational therapeutics. Dr. Tempero has served on the ASCO Board of Directors and as ASCO President. She currently serves on the ASCO Conquer Cancer Foundation Board. She codirected the AACR/ASCO Methods in Clinical Cancer Research and taught this course and similar courses in Europe and Australia. She was founding Chair of the $\mathrm{NCl}$ Clinical Oncology Study Section and served as a member and Chair of the NCl Board of Scientific Counselors Subcommittee A. She is a member of the Scientific Steering Committee and Chair of the Clinical and Translational Study Section for the Cancer Prevention \& Research Institute of Texas. She is or has been on the Scientific Advisory Boards of the Lustgarten Foundation, the Pancreatic Cancer Action Network, the V Foundation, The Alberta Canada Cancer Board, and the EORTC. She served as a member of the Oncology Drug Advisory Committee for the FDA. She has served as Deputy Director and Interim Director for the UNMC Eppley Cancer Center. She is Chief Emeritus of the Division of Medical Oncology at UCSF and served as the founding Deputy Director and Director of Research Programs at the UCSF Helen Diller Family Comprehensive Cancer Center.

doi: $10.6004 /$ jnccn.2018.0080

The ideas and viewpoints expressed in this editorial are those of the author and do not necessarily represent any policy, position, or program of NCCN. 